A. K. Geim e A. H. MacDonald, Graphene: Exploring carbon flatland, Physics Today 60, 35 (2007)

A. K. Geim e Philip Kim, Carbon wonderland, Scientific American 298, 68 (2008)

A. K. Geim, Graphene: Status and Prospects, Science 324, 1530 (2009).

N. M. R. Peres, Graphene, new physics in two dimensions, Europhysics News 40, 17 (2009).

A. H. Castro Neto, F. Guinea, N. M. R. Peres K. S. Novoselov and A. K. Geim, The electronic properties of graphene, Reviews of Modern Physics 81, 109 (2009) .

N. M. R. Peres, Colloquium: The transport properties of graphene: An introduction, Re- views of Modern Physics 82, 2673 (2010).

\section{N. M. R. Peres}

Departamento de Física e CFUM, Universidade do Minho, P-4710-057 Braga

\section{J. M. B. Lopes dos Santos}

CFP e Departamento de Física e Astronomia, Faculdade de Ciências da Universidade do Porto, P-4169-007, Porto

\title{
Ulrich Schubert Eleito Novo Presidente da EuCheMS
}

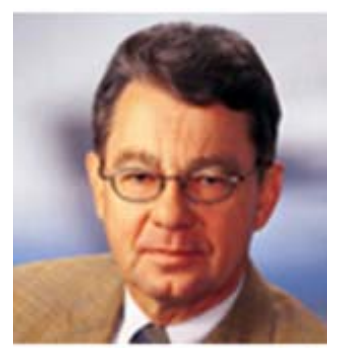

Em Outubro de 2011, Ulrich Schubert irá suceder a Luis Oro como Presidente da EuCheMS, após eleição pela Assembleia Geral da EuCheMS, realizada em Bled, Eslovénia.

Ulrich Schubert serviu a comunidade científica como Vice-Presidente da Sociedade Austríaca de Química entre 1998 e 2000 e como Presidente entre 2000 e 2004. Durante este período iniciou a $1^{\text {a }}$ Semana Austríaca de Química. É director da Organização

\section{Medições na Ciência ena TeCnOLogia}

Nos dias 4 e 5 de Novembro de 2010 , realizou-se, na Faculdade de Ciências da Universidade de Lisboa, a $1^{\mathrm{a}}$ Conferência Nacional de Metrologia, CONFMET 2010 com o tema adoptado internacionalmente para o ano de 2010, Medições na Ciência e na Tecnologia. O acontecimento foi patrocinado pela SPMet, Sociedade Portuguesa de Metrologia, pela RELACRE, Rede de Laboratórios Acreditados, e pela SPQ, Sociedade Portuguesa de Química, inserindo-se nos respectivos objectivos de promover a expansão do ensino, da investigação científica e da divulgação da Metrologia Física e Química, contribuindo para a credibilização dos resultados das medições. A Comissão Organizadora e a Comissão Científica contaram com membros da três instituições. Os trabalhos desenrolaram-se em oito sessões com apresentações orais e em
Nacional Aderente da IUPAC na Áustria. Integrou vários painéis de revisão e de avaliação da União Europeia, do Conselho Europeu de Investigação, da rede ERA-Chemistry e de vários países Europeus. É actualmente membro do Conselho Executivo do Fundo Austríaco da Ciência, do Senado da Sociedade Austríaca de Investigação Christian-Doppler e do comité de decisão da Iniciativa Alemã para a Excelência.

Ulrich Schubert é Professor de Química Inorgânica no Instituto de Química dos Materiais da Universidade de Tecnologia de Viena. Os seus interesses de investigação centram-se nos materiais híbridos inorgânicos-orgânicos,

poster, constando a sessão de abertura dos cumprimentos de boas vindas aos participante seguidos da Lição "Ciência da Medição em Química". Enquanto a Metrologia Física é um tema já bastante consolidado no meio científico, a Metrologia Química, de enorme expansão e importância num mundo actual onde os resultados de medições químicas dominam a Economia e a Sociedade, tem-se desenvolvido enormemente ao longo das últimas décadas, o que justificou esta opção. Seguiram-se as sessões sobre Incertezas das Medições, Metrologia e Gestão, Medições na Ciência e na Tecnologia, que integrou um animado e importante debate sobre Comparabilidade das Medições em Química, Metrologia em Química, Posters, Calibração e Ensaio e, antes do encerramento, uma sessão de divulgação e debate a cargo da IMEKO, Interna- desde a química dos precursores às aplicações. Possui também um forte background na química organometálica e do silício. Supervisionou cerca de 75 estudantes de doutoramento de 11 nacionalidades diferentes e os resultados científicos do seu grupo estão documentados em mais de 450 artigos, incluindo vários artigos de revisão e alguns livros. É membro da Academia Austríaca das Ciências e da Academia Alemã Leopoldina.

Para mais informações consultar: http://info.tuwien.ac.at/inorganic/staff/ pers_schubert_e.php.

(Fonte: EuCheMS) HG

tional Measurement Confederation, cujas comissões técnicas englobam membros portugueses e que teve o seu congresso anual em Lisboa, em 2009. A Sessão de Posters teve a originalidade de contar com uma pequena apresentação pelos autores, junto do trabalho respectivo, que enriqueceu a comunicação com os participantes. Antes do encerramento foram anunciadas novas iniciativas para $o$ futuro próximo, designadamente para 2011, ano rico em efemérides nacionais e internacionais, designadamente em Química. Salienta-se a workshop "Desenvolvimentos Recentes em Incerteza das Medições" organizada pelo Grupo de Trabalho Eurachem/CITAC sobre Medição de Incerteza e Rastreabilidade que terá lugar em Lisboa de 6 a 7 de Junho.

MFC 